\title{
Raman Spectra of Isotope-substituted Mitochondria of Living Budding Yeast Cells: Possible Origin of the "Raman Spectroscopic Signature of Life"
}

\author{
Chikao Onogi, ${ }^{1}$ Hajime Torii, ${ }^{2}$ and Hiro-o Hamaguchi*1,3 \\ ${ }^{1}$ Department of Chemistry, School of Science, The University of Tokyo, 7-3-1 Hongo, Bunkyo-ku, Tokyo 113-0033 \\ ${ }^{2}$ Department of Chemistry, School of Education, Shizuoka University, 836 Ohya, Shizuoka 422-8529 \\ ${ }^{3}$ Institute of Molecular Science and Department of Applied Chemistry, National Chiao Tung University, \\ 1001 Ta Hsueh Road, Hsinchu, Taiwan 300
}

(Received June 25, 2009; CL-090598; E-mail: hhama@chem.s.u-tokyo.ac.jp)

The ${ }^{13} \mathrm{C}$ and ${ }^{2} \mathrm{H}$ isotope substitution effects have been examined for the "Raman spectroscopic signature of life," a mitochondrial Raman band at $1602 \mathrm{~cm}^{-1}$ that sharply reflects the metabolic activity of living yeast cells. The band shifts to $1542 \mathrm{~cm}^{-1}$ with ${ }^{13} \mathrm{C}$ substitution and to $1599 \mathrm{~cm}^{-1}$ with ${ }^{2} \mathrm{H}$ substitution. Normal mode analysis based on a DFT calculation suggests that it originates from a $\mathrm{C}=\mathrm{C}$ double bond having no hydrogen atoms attached to the carbon atoms. The in-phase $\mathrm{C}=\mathrm{C}$ stretch mode of ubisemiquinone radicals ( $\mathrm{CoQ}$ and/or $\mathrm{CoQH}^{*}$ ) emerges as a strong candidate for the origin of the $1602 \mathrm{~cm}^{-1}$ band.

In vivo, noninvasive and molecular-level monitoring of cellular metabolic activity is crucially important for the future development of quantitative physical chemistry looking at life. The "Raman spectroscopic signature of life," which is a strong and sharp Raman band at $1602 \mathrm{~cm}^{-1}$ measured from mitochondria of living yeast cells, ${ }^{1,2}$ has great potential as a reliable molecular indicator of metabolic activity. This band has been shown to reflect cellular metabolic activity in many different ways, sharply responding to respiration inhibition, ${ }^{2,3}$ starvation, ${ }^{4}$ oxidative stress, ${ }^{5}$ and anaerobic culture.$^{5}$ However, the origin of this $1602 \mathrm{~cm}^{-1}$ band is yet to be made clear. In the present study, we examine the Raman spectra of ${ }^{13} \mathrm{C}$ and ${ }^{2} \mathrm{H}$ isotope-substituted mitochondria in living yeast cells, in order to identify the origin of the "Raman spectroscopic signature of life." Isotope effects are observed as shifts of vibrational frequencies induced by the change of atomic mass. They provide a reliable experimental basis for band assignments of Raman and infrared spectra.

A tetraploid strain of budding yeast, a zygote of Saccharomyces cerevisiae and Saccharomyces bayanus, was used in the present study. It was a gift from Suntory Co., Ltd. Cells were cultured at $30^{\circ} \mathrm{C}$ in SC medium, which was a synthetic complete medium containing $2 \%$ D-glucose, $0.67 \%$ Bacto-yeast nitrogen base without amino acids, and $0.2 \%$ Drop-out mixture of amino acids. For isotope substitution experiments, ${ }^{13} \mathrm{C}$-substituted Dglucose and ${ }^{2} \mathrm{H}$-substituted D-glucose (Cambridge Isotope Laboratories, Inc.) were used. Raman spectroscopic measurements were carried out for yeast cells sampled in the stationary state after an overnight $(24 \mathrm{~h})$ culturing. In the isotope-substituted experiments, the overnight culturing was carried out twice. No changes of Raman spectra were found between these two consecutive culturings, indicating that the isotope substitution was already complete in the first overnight culturing. Raman spectra of mitochondria were recorded on a laboratory built confocal Raman microspectrometer. The details of the apparatus are described in our previous reports. ${ }^{1-5}$ The excitation line was the
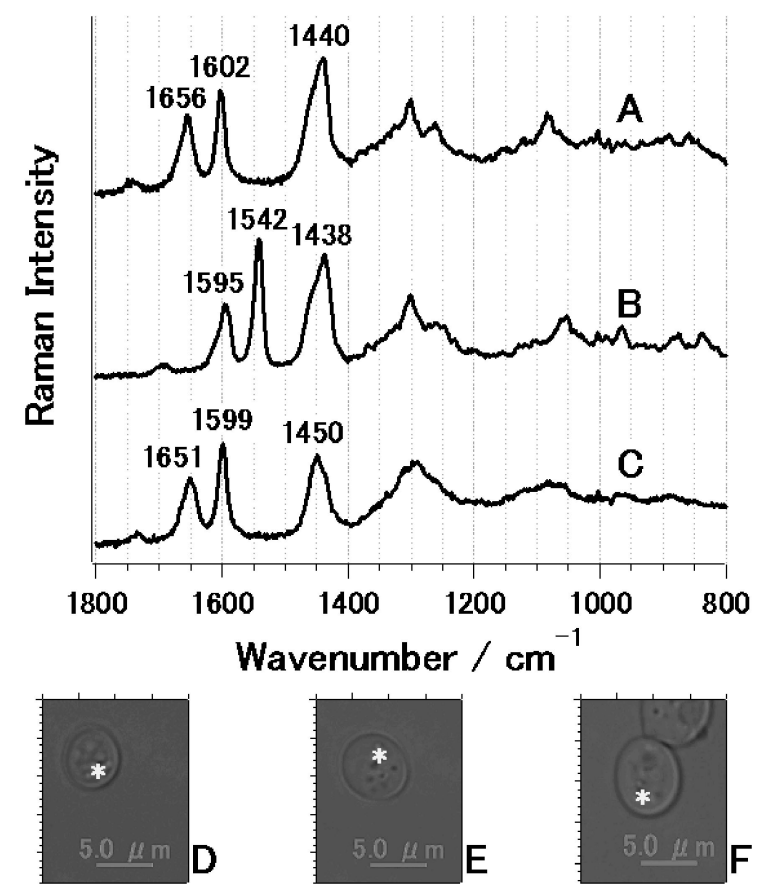

Figure 1. Space-resolved Raman spectra of budding yeast cell in (A) unsubstituted medium, (B) ${ }^{13} \mathrm{C}$-substituted D-glucose medium, (C) deuterium-substituted D-glucose medium. The optical microscopic images, D, E, and F indicate the points of the laser spot $\left(^{*}\right)$ where $\mathrm{A}, \mathrm{B}$, and $\mathrm{C}$ were measured.

$632.8 \mathrm{~nm}$ line of a He-Ne laser. The spatial resolution was $300 \mathrm{~nm}$ in the lateral direction and $2 \mu \mathrm{m}$ in the axial. The 400 $1800 \mathrm{~cm}^{-1}$ wavenumber region was measured with a spectral resolution of $3 \mathrm{~cm}^{-1}$. Accumulation time was $300 \mathrm{~s}$ with excitation laser power of $6 \mathrm{~mW}$ at the sample point.

Space-resolved Raman spectra of mitochondria in single living budding yeast cells are shown in Figure 1. Figure 1A shows the Raman spectrum of a cell cultured in ordinary SC medium, Figure $1 \mathrm{~B}$ shows that in $\mathrm{SC}$ medium containing ${ }^{13} \mathrm{C}$-substituted D-glucose, and Figure $1 \mathrm{C}$ with ${ }^{2} \mathrm{H}$-substituted D-glucose. The optical microscopic images, D, E, and F indicate the points of the laser spot where Raman spectra A, B, and C were measured, respectively.

The spectrum A shows a number of Raman bands that are already assigned to phospholipids. ${ }^{3}$ The band at $1440 \mathrm{~cm}^{-1}$ is assigned to the $\mathrm{C}-\mathrm{H}$ bend modes of methyl and methylene groups. The $1656 \mathrm{~cm}^{-1}$ band is due to the $c i s-\mathrm{C}=\mathrm{C}$ stretch mode of unsaturated chains of phospholipids. Between these two prominent bands of phospholipids, the "Raman spectroscopic signature of 
life" is observed at $1602 \mathrm{~cm}^{-1}$. As seen from Figures 1B and 1C, these three bands show clear isotope shifts. The $1656 \mathrm{~cm}^{-1}$ band (cis- $\mathrm{C}=\mathrm{C}$ stretch) in Figure $1 \mathrm{~A}$ completely disappears in Figure 1B, indicating that all carbon atoms of phospholipids are replaced under culturing with ${ }^{13} \mathrm{C}$-substituted D-glucose. The band at $1595 \mathrm{~cm}^{-1}$ in Figure $1 \mathrm{~B}$ is assigned to the cis${ }^{13} \mathrm{C}={ }^{13} \mathrm{C}$ stretch, for the shift of $61 \mathrm{~cm}^{-1}(1656-1595=$ $\left.61 \mathrm{~cm}^{-1}\right)$ is exactly what is expected for a $\mathrm{C}=\mathrm{C}$ stretch mode (See the following discussion based on a DFT calculation). Then, it is straightforward to assign the strong $1542 \mathrm{~cm}^{-1}$ band in Figure $1 \mathrm{~B}$ to the ${ }^{13} \mathrm{C}$-substituted "Raman spectroscopic signature of life." Note that ${ }^{13} \mathrm{C}$ substitution does not change much the normal modes and the electronic structure of molecules so that Raman spectral patterns are generally well preserved. The shift of $60 \mathrm{~cm}^{-1}\left(1602-1542=60 \mathrm{~cm}^{-1}\right)$ suggests that the 1602 $\mathrm{cm}^{-1}$ band also originates from a $\mathrm{C}=\mathrm{C}$ double bond.

The effect of ${ }^{2} \mathrm{H}$ substitution is much less substantial than that of ${ }^{13} \mathrm{C}$ substitution. The cis- $\mathrm{C}=\mathrm{C}$ stretch band shifts down by $5 \mathrm{~cm}^{-1}$ (1656 to $1651 \mathrm{~cm}^{-1}$ ) and the $1602 \mathrm{~cm}^{-1}$ band shifts down only by 3 to $1599 \mathrm{~cm}^{-1}$. These small ${ }^{2} \mathrm{H}$ shifts are not due to incomplete ${ }^{2} \mathrm{H}$ substitution in the experiment, as already proven above. The $10 \mathrm{~cm}^{-1}$ upshift of the $1440 \mathrm{~cm}^{-1}$ band to $1450 \mathrm{~cm}^{-1}$ indicates that most of the $\mathrm{CH}$ bend bands shift down to ca. $1100 \mathrm{~cm}^{-1}$ region, and the remaining $\mathrm{CH}$-bend bands, which are mostly protein $\mathrm{CH}$ bend bands, have higher frequencies around $1450 \mathrm{~cm}^{-1}$. Note that proteins are mostly synthesized from amino acids and that the hydrogen atoms in proteins may not be substituted under ${ }^{2} \mathrm{H}$ D-glucose culturing.

The very small ${ }^{2} \mathrm{H}$ shifts in the 1656 and $1602 \mathrm{~cm}^{-1}$ bands are intriguing. Here we focus on the $1602 \mathrm{~cm}^{-1}$ band, whose assignment is the primary interest in this letter; the $1656 \mathrm{~cm}^{-1}$ band will be discussed in a separate paper. We know empirically that ${ }^{2} \mathrm{H}$ shifts of the $\mathrm{C}=\mathrm{C}$ stretch modes of olefins are much larger than $3 \mathrm{~cm}^{-1}$. ${ }^{6}$ This trend is confirmed by a DFT calculation. Table 1 shows the ${ }^{13} \mathrm{C}$ and ${ }^{2} \mathrm{H}$ shifts for the $\mathrm{C}=\mathrm{C}$ stretch modes of cis- and trans-2-butene and 2-methyl-2-butene calculated at the B3LYP/6-31+G(2df,p) level. The calculated ${ }^{13} \mathrm{C}$ shifts are all very close to $60 \mathrm{~cm}^{-1}$ as expected from the ${ }^{13} \mathrm{C} /{ }^{12} \mathrm{C}$ mass ratio. They accord very well with the observed shift of the $1602 \mathrm{~cm}^{-1}$ band as well. The ${ }^{2} \mathrm{H}$ shifts are 26.2 and $32.8 \mathrm{~cm}^{-1}$ for cis- and trans-2-butene and $13.0 \mathrm{~cm}^{-1}$ for 2-methyl-2-butene. The smallest shift, $13.0 \mathrm{~cm}^{-1}$ for 2-methyl-2-butene, is still much larger than $3 \mathrm{~cm}^{-1}$. We, therefore, argue that the 1602 $\mathrm{cm}^{-1}$ band originates from a $\mathrm{C}=\mathrm{C}$ bond with no hydrogen atoms attached to the carbon atoms.

The $\mathrm{C}=\mathrm{C}$ double bond in a quinoid ring is an obvious candidate for such a $\mathrm{C}=\mathrm{C}$ bond without any hydrogen attached to it. Here we consider the ubisemiquinone radical anion $\left(\mathrm{CoQ}^{-\cdot}\right.$, Figure 2) as possible origin of the $1602 \mathrm{~cm}^{-1}$ band. According to a pulse radiolysis experiment, ${ }^{7}$ the transient Raman spectrum of the 2,5-dichloro- $p$-benzosemiquinone radical anion has a

Table 1. The ${ }^{13} \mathrm{C}$ and ${ }^{2} \mathrm{H}$ isotope shifts of the $\mathrm{C}=\mathrm{C}$ stretch frequency of cis-2-butene, trans-2-butene, and 2-methyl-2-butene calculated at the B3LYP/6-31+G(2df,p) level

\begin{tabular}{lcl}
\hline & ${ }^{13} \mathrm{C}$ shift & ${ }^{2} \mathrm{H}$ shift \\
\hline cis-2-butene & -60.0 & -26.2 \\
trans-2-butene & -60.0 & -32.8 \\
2-methyl-2-butene & -60.7 & -13.0 \\
\hline
\end{tabular}<smiles>CCC/C(C)=C/CCc1c(C)c(=O)c(OC)c(OC)[c-]1[O-]</smiles>

Figure 2. Molecular structure of the ubisemiquinone radical anion $\left(\mathrm{CoQ}^{-*}\right)$. The number of $n$ takes values from 6 to 10 . Fission yeast cell has $n=10$ and budding yeast cell has $n=6$.

strong and sharp band at $1602 \mathrm{~cm}^{-1}$, which is assigned to the in-phase $\mathrm{C}=\mathrm{C}$ stretch mode of the quinoid ring. The spectrum shows a number of extra Raman bands in the wavenumber region lower than $1600 \mathrm{~cm}^{-1}$. However, the intensities of these bands are much lower than that of the $1602 \mathrm{~cm}^{-1}$ band, and, therefore, they may well be invisible in the Raman spectra of mitochondria. Resonance Raman spectra of electrolyzed CoQ10 also show strong isolated bands around $1600 \mathrm{~cm}^{-1}$, which are assigned to the quinoid ring $\mathrm{C}=\mathrm{C}$ stretch modes. ${ }^{8}$ We have yet to observe the ${ }^{13} \mathrm{C}$ and ${ }^{2} \mathrm{H}$ shift of the $1602 \mathrm{~cm}^{-1}$ band of this radical but all the vibrational data presented here are consistent with the assignment of the "Raman spectroscopic signature of life" to $\mathrm{CoQ}^{-\bullet}$

Ubiquinone (CoQ) plays an essential role as an electron carrier between Complex I, II, and III in the electron-transport chain in mitochondria. In the electron-transport process, the $\mathrm{CoQ}^{-}$. and/or its protonated form $\left(\mathrm{CoQH}^{*}\right)$ appear as intermediates between $\mathrm{CoQ}$ and the reduced form ubiquinol $\left(\mathrm{CoQH}_{2}\right)$. The higher the metabolic activity in mitochondria is, the higher the concentrations of these intermediates. Thus, if the $1602 \mathrm{~cm}^{-1}$ band originates from $\mathrm{CoQ}^{-\bullet}$ and/or $\mathrm{CoQH}$, its sensitivity to the cellular metabolic activity is very well accounted for.

In vivo Raman measurements of isotope-substituted yeast cells have provided us with crucial information on the identity of the so far unassigned band at $1602 \mathrm{~cm}^{-1}$, the "Raman spectroscopic signature of life." With the help of a normal mode analysis, we have come to a thought that $\mathrm{CoQ}^{-\cdot}$ and/or $\mathrm{CoQH}^{\cdot}$ is the origin of this intriguing Raman signature. Further studies are now in progress to establish this assignment by the isotope substitution of $\mathrm{CoQ}^{-\cdot}$ and $\mathrm{CoQH}$.

The authors thank Dr. Kaliaperumal Venkatesh and Mr. Liang-da Chiu for stimulating discussion. They are also grateful to Dr. Fumihiko Omura and Ms. Hideko Yomo (Suntory Co., Ltd.) for providing us with the yeast strain.

\section{References}

1 Y.-S. Huang, T. Karashima, M. Yamamoto, H. Hamaguchi, J. Raman Spectrosc. 2003, 34, 1.

2 Y.-S. Huang, T. Karashima, M. Yamamoto, T. Ogura, H. Hamaguchi, J. Raman Spectrosc. 2004, 35, 525.

3 Y.-S. Huang, T. Karashima, M. Yamamoto, H. Hamaguchi, Biochemistry 2005, 44, 10009.

4 Y. Naito, A. Toh-e, H. Hamaguchi, J. Raman Spectrosc. 2005, 36, 837.

5 Y.-S. Huang, T. Nakatsuka, H. Hamaguchi, Appl. Spectrosc. 2007, 61, 1290.

6 T. Shimanouchi, Tables of Molecular Vibrational Frequencies, Consolidated Volume I, NSRDS-NBS 39, National Bureau of Standards, USA, 1972

7 G. N. R. Tripathi, R. H. Schuler, J. Chem. Phys. 1982, 76, 2139.

8 X. Zhao, T. Ogura, M. Okamura, T. Kitagawa, J. Am. Chem. Soc. 1997, $119,5263$. 